\title{
RTEL1 polymorphisms are associated with lung cancer risk in the Chinese Han population
}

\author{
Shouchun Yan ${ }^{1,2}$, Ridong Xia ${ }^{3,4,5}$, Tianbo Jin ${ }^{3,4,5,6}$, Hui Ren ${ }^{1}$, Hua Yang ${ }^{6}$, Jing Li ${ }^{6}$, \\ Mengdan Yan ${ }^{6}$, Yuanyuan Zhu' ${ }^{6}$, Mingwei Chen ${ }^{1}$ \\ ${ }^{1}$ Department of Respiratory and Critical Care Medicine, The First Affiliated Hospital of Xi'an Jiaotong University, Xi'an, \\ Shaanxi 710061, China \\ ${ }^{2}$ Department of Emergency Medicine, Xi'an NO.1 Hospital, Xi'an, Shaanxi 710002, China \\ ${ }^{3}$ Key Laboratory of Molecular Mechanism and Intervention Research for Plateau Diseases of Tibet Autonomous Region, \\ School of Medicine, Xizang Minzu University, Xianyang, Shaanxi 712082, China \\ ${ }^{4}$ Key Laboratory of High Altitude Environment and Genes Related to Diseases of Tibet Autonomous Region, School of \\ Medicine, Xizang Minzu University, Xianyang, Shaanxi 712082, China \\ ${ }^{5}$ Key Laboratory for Basic Life Science Research of Tibet Autonomous Region, School of Medicine, Xizang Minzu University, \\ Xianyang, Shaanxi 712082, China \\ ${ }^{6}$ School of Life Sciences, Northwest University, Xi'an, Shaanxi 710069, China
}

Correspondence to: Mingwei Chen, email: chen_mingwei1964@163.com

Keywords: single nucleotide polymorphism, RTEL1, lung cancer, case-control study, Chinese Han

Received: June 01, 2016 Accepted: August 26, $2016 \quad$ Published: September 28, 2016

\section{ABSTRACT}

RTEL1 (regulator of telomere elongation helicase 1; OMIM 608833) gene polymorphisms were linked to lung cancer (LC) susceptibility in a cancer genomewide association study (GWAS) Here, we assessed whether seven previously reported RTEL1 polymorphisms influenced LC risk in Han Chinese population. All study samples (554 LC cases and 696 cancer-free controls) were collected from the Affiliated Hospital of Xizang Minzu University in China. We assessed associations between SNPs and LC risk using various several genetic models (codominant, dominant, recessive, overdominant, and additive). Whereas rs 2738780 showed a protective effect against LC (Odds ratio $(O R)=0.80 ; 95 \%$ confidence interval $(C I): 0.638=0.998 ; p=0.048)$, rs7261546(OR = 4.16; 95\% CI: 1.35-12.82; $p=0.007)$, rs6062299(OR=5.08; 95\% CI: 1.43-18.10; $p=0.005$ ) and rs3787098(OR = 5.10; 95\% CI: 1.43-18.15; $p=0.004$ ) were all associated with increased LC susceptibility (recessive model). Haplotype analysis suggested that "CTC" was associated with a 0.8 -fold decrease in LC risk (OR $=0.80,95 \% \mathrm{CI}, 0.63-1.00$; Pearson's $p=0.05)$. These findings suggest a potential association between RTEL1 polymorphisms and LC risk in a Chinese Han population.

\section{INTRODUCTION}

Lung Cancer (LC) is differentiated into four major histologic classes, including adenocarcinoma, squamous cell carcinoma, small cell carcinoma and large cell carcinoma [1]. LC is the leading cause of cancer mortality worldwide, with a death rate in China of $39.54 / 100,000$ [2]. Despite recent chemotherapy advances, there is no effective method for treating LC [3]

Causes of lung cancer are diverse, and include active and passive smoking, ionizing radiation exposure, arsenic, aromatic hydrocarbons, genetic predisposition, lifestyle, diet and pre-existing nonmalignant lung diseases, such as idiopathic pulmonary fibrosis and tuberculosis [4]. Genetic predisposition frequently plays an extremely important role in the occurrence of cancer. Incidences of rare alleles are significantly higher in cancer patients than controls, suggesting that these alleles predisposed patients to tumors $[5,6]$. Multiple RTEL1 (regulator of telomere elongation helicase 1) gene mutants appear e relevant to LC [7].

RTEL1 plays a crucial role in cancers, including LC, and in hereditary diseases, such as Hoyeraal-Hreidarsson syndrome [8, 9]. Cancer genome-wide association studies (GWAS) showed that RTEL1 polymorphisms 
contribute to LC risk [10-12]. RTEL1 SNPs, rs2297434, rs7261546, rs2738780, rs6062299, s2777937, rs3787098 and rs2297440, have not yet been studied with respect to LC. The present study was performed to evaluate the association of these seven SNPs with LC risk in the Chinese population.

\section{RESULTS}

\section{Subject characteristics}

The study was carried out on 554 LC patients (138 female, $24.9 \% ; 416$ male, $75.1 \%$ ) and 696 controls (304 female, 43.7\%; 392 male, 56.3\%). Median age was 58.1 years (24-85) for the case group and 48.6 years (1882 ) for the control group. For smoking status, individuals who smoked $<2$ cigarettes per week or $<100$ per year were defined as non-smoking; otherwise, individuals were considered smoking. For alcohol drinking, more than once per week in the past six months was considered to be drinking; otherwise, individuals were considered nondrinking. We found that gender, age and smoking status, but not drinking status, was significant in both groups $(p<0.05$, Table 1$)$.

\section{Associations between individual SNPs and LC risk}

We tested six SNPs for association with LC risk in cases and controls. One SNP (rs2297440) was excluded for deviation from Hardy-Weinberg equilibrium $(p<0.01)$. We used the chi-squared test to assess the influence of gene polymorphism on LC risk in the allele model, and found that RTEL1 rs 2738780 reduced LC risk OR $=0.80$ 95\% CI: 0.638-0.998, $p=0.048$, Table 2).

We also used unconditional logistic regression analysis in five genetic models (co-dominant, dominant, recessive, over-dominant and log-additive) to appraise the association between each SNP and LC risk (Table 3). The best inheritance model was assessed using Akaike information criteria (AIC) and Bayesian information criteria (BIC), with the model with the lowest values being the best fit [13]. ' $\mathrm{C} / \mathrm{C}-\mathrm{G} / \mathrm{C}$ ' of rs7261546, ' $\mathrm{C} / \mathrm{C}$ ' of rs6062299 and 'A/A' of rs3787098 increased LC risk, and exerted a recessive effect $(p=0.007, \mathrm{OR}=4.16,95 \% \mathrm{CI}$ : $1.35-12.82 ; p=0.005, \mathrm{OR}=5.08,95 \% \mathrm{CI}: 1.43-18.10$; $p=0.004, \mathrm{OR}=5.10,95 \% \mathrm{CI}: 1.43-18.15$, respectively; Table 3). In the additive model, allele ' $G$ ' in rs 2853672 had a protective effect $(p=0.044, \mathrm{OR}=0.66,95 \%$ CI: 0.45-0.97).

\section{Linkage disequilibrium of RTEL1 SNPs}

Linkage disequilibrium (LD) analysis identified three haplotype blocks on chromosome 20, and three RTEL1 SNPs formed a block within $11 \mathrm{~kb}$ (chr: 2297434 2777937). RTEL1 SNP LD patterns by Haploview analysis are shown in Figure 1. We investigated associations between different haplotypes using the three RTEL1 SNPs (rs2297434 rs2738780 rs2777937) and found that the haplotype "CTC" was associated with 0.8-fold decreased $\mathrm{LC}$ risk $(\mathrm{OR}=0.80,95 \%$ CI, 0.63-1.00, Pearson's $p=0.05$ ) Table 4 .

\section{DISCUSSION}

RTEL1 is an ATP-dependent DNA helicase that was initially identified in mice as a dominant telomere length regulator [14]. Telomeres are guanine-rich tandem DNA repeats (TTAGGG repeats in mammals) located at the ends of linear chromosomes. The shelterin complex is essential to protect telomeres from degradation and from DNA repair mechanisms that might otherwise mistakenly remove and "repair" telomeric DNA [15]. Human

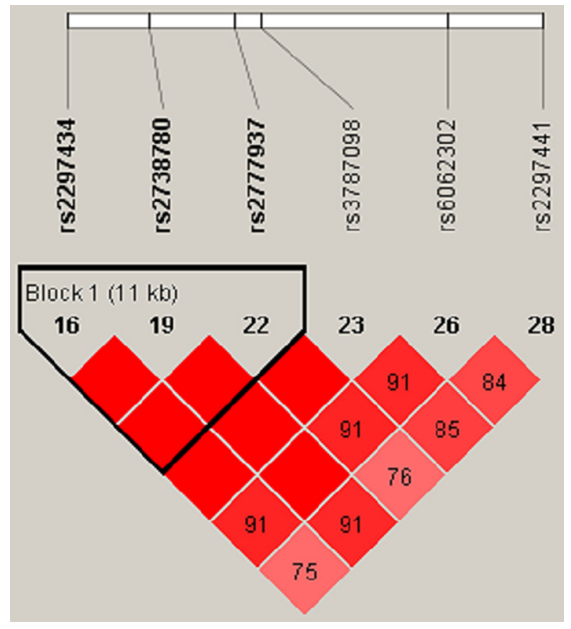

Figure 1: Linkage disequilibrium (LD) of all $\boldsymbol{R} T E L 1$ polymorphic sites. Brighter red represents stronger $L D\left(L O D=2, D^{\prime}=1\right)$. Numbers inside boxes represent LD $\mathrm{r}^{2}$ values. 
Table 1: Distributions of select characteristics by case-control status

\begin{tabular}{lccc}
\hline \multicolumn{1}{c}{ Variable } & Cases $(\mathbf{n}=\mathbf{5 5 4})$ & Controls $(\mathbf{n}=\mathbf{6 9 6})$ & $\boldsymbol{p}$-value \\
\hline Sex & & & $p<0.001 \mathrm{a}$ \\
Male & 416 & 392 & \\
Female & 138 & 304 & $p<0.001 \mathrm{a}$ \\
Smoking status & & & \\
Smoking & 352 & 293 & \\
Non-Smoking & 202 & 403 & 0.35 \\
Drinking status & & & \\
Drinking & 147 & 173 & \\
Non-drinking & 407 & 423 & \\
Age, year (mean $\pm \mathrm{SD})$ & $58.1 \pm 10.5$ & $48.6 \pm 0.05 \mathrm{~b}$ \\
\hline
\end{tabular}

${ }^{a} p$ values were calculated from Chi-square tests.

${ }^{b} p$ values were calculated by Student' $t$ tests.

Table 2: RTEL1 SNPs analyzed in this study

\begin{tabular}{llccccccc}
\hline SNP ID & Gene & $\begin{array}{c}\text { Chromosome } \\
\text { position }\end{array}$ & $\begin{array}{c}\text { Base } \\
\text { change }\end{array}$ & $\begin{array}{c}\text { MAF- } \\
\text { case }\end{array}$ & $\begin{array}{c}\text { MAF- } \\
\text { control }\end{array}$ & $\begin{array}{c}\text { HWE } \\
\boldsymbol{p} \text {-value }\end{array}$ & OR (95\% CI) & $\boldsymbol{p}$ value \\
\hline rs2297434 & RTEL1 & 20.00 & T/C & 0.13 & 0.12 & 1.000 & $1.051(0.826-1.335)$ & 0.688 \\
rs7261546 & RTEL1 & 20.00 & G/C & 0.13 & 0.12 & 0.043 & $1.145(0.903-1.453)$ & 0.264 \\
rs2738780 & RTEL1 & 20.00 & T/C & 0.14 & 0.16 & 0.405 & $0.798(0.638-0.998)$ & $0.048^{*}$ \\
rs6062299 & RTEL1 & 20.00 & C/G & 0.13 & 0.12 & 0.015 & $1.135(0.892-1.443)$ & 0.302 \\
rs2777937 & RTEL1 & 20.00 & T/C & 0.13 & 0.12 & 1.000 & $1.045(0.822-1.327)$ & 0.719 \\
rs3787098 & RTEL1 & 20.00 & $\mathrm{~A} / \mathrm{G}$ & 0.12 & 0.11 & 0.068 & $1.141(0.888-1.465)$ & 0.303 \\
rs2297440 & RTEL1 & 20.00 & $\mathrm{C} / \mathrm{T}$ & 0.26 & 0.24 & 0.0122 & $1.149(0.958-1.379)$ & 0.135 \\
\hline
\end{tabular}

*Site with HWE $P \leq 0.01$ excluded.

HWE, Hardy-Weinberg equilibrium; MAF, minor allele frequency; OR, odds ratio; CI, confidence interval;

SNP, single-nucleotide polymorphism.

$* p \leq 0.05$ indicates statistical significance.

telomeres are about $10-15 \mathrm{~kb}$ in length and are shortened by 30 to $200 \mathrm{bp}$ each cell division, due to incomplete replication of linear DNA molecules and the absence of a chromosome end replication mechanism [16]. Telomere shortening may underlie chromosome instability in tumor cells. Multiple lines of evidence support the hypothesis that telomere dysfunction promotes genetic changes required for tumorigenesis and malignant progression [17]. In the absence of RTEL1, telomeres are not maintained and chromosome fusions are observed.

In our case-control study, we evaluated seven SNPs associated with LC susceptibility in a Chinese Han population and our found that rs2738780 and the "CTC" haplotype are associated with decreased LC risk. The RTEL1 gene, located on 20q13.3, encodes an essential helicase that plays a crucial role in mitotic and meiotic DNA double-stranded break repair [18, 20]. Double-stranded break functional consequences include oncogene activation, as in many leukemias, lymphomas and sarcomas, and tumor suppressor loss or inactivation, as in many solid tumors and most carcinomas [21, 22]. RTEL1 is expected to act as a tumor suppressor. However, as indicated by human genetic data, the RTEL1 genomic locus $(20 q 13.3)$ is frequently amplified in human cancers [23-25], and ted RTEL1 upregulation could be important for tumorigenesis. Cancer GWAS have linked RTEL1 mutation to LC [10-12].

$$
\text { RTEL1 rs3787098 allele frequency }
$$
has been associated with glioblastoma risk in the Chinese Han population [26]. In the current study, we found that genotype 'A/A' of rs3787098 was associated with increased LC risk. How SNP rs3787098 affects pathogenesis in various cancer types still needs further study. In a meta-analysis, Zhang, et al. [27] found that the rs2297440 polymorphism moderately increased glioma risk in all genetic models. 
Table 3: Relationship between rs2297440 alleles and LC risk in different genetic models

\begin{tabular}{|c|c|c|c|c|c|c|}
\hline SNP & Model & Genotype & $\begin{array}{l}\text { group = } \\
\text { control }\end{array}$ & group $=$ case & OR (95\% CI) & $p$-value \\
\hline \multirow{10}{*}{ rs7261546 } & Codominant & $\mathrm{C} / \mathrm{C}$ & $536(77 \%)$ & $420(75.8 \%)$ & 1 & 0.025 \\
\hline & & $\mathrm{G} / \mathrm{C}$ & $156(22.4 \%)$ & $121(21.8 \%)$ & $0.99(0.76-1.30)$ & \\
\hline & & $\mathrm{G} / \mathrm{G}$ & $4(0.6 \%)$ & $13(2.4 \%)$ & $4.15(1.34-12.81)$ & \\
\hline & Dominant & $\mathrm{C} / \mathrm{C}$ & $536(77 \%)$ & $420(75.8 \%)$ & 1 & 0.62 \\
\hline & & $\mathrm{G} / \mathrm{C}-\mathrm{G} / \mathrm{G}$ & $160(23 \%)$ & $134(24.2 \%)$ & $1.07(0.82-1.39)$ & \\
\hline & Recessive & $\mathrm{C} / \mathrm{C}-\mathrm{G} / \mathrm{C}$ & $692(99.4 \%)$ & $541(97.7 \%)$ & 1 & $0.007 *$ \\
\hline & & $\mathrm{G} / \mathrm{G}$ & $4(0.6 \%)$ & $13(2.4 \%)$ & $4.16(1.35-12.82)$ & \\
\hline & Overdominant & $\mathrm{C} / \mathrm{C}-\mathrm{G} / \mathrm{G}$ & $540(77.6 \%)$ & $433(78.2 \%)$ & 1 & 0.81 \\
\hline & & $\mathrm{G} / \mathrm{C}$ & $156(22.4 \%)$ & $121(21.8 \%)$ & $0.97(0.74-1.27)$ & \\
\hline & Log-additive & --- & --- & --- & $1.15(0.90-1.46)$ & 0.26 \\
\hline \multirow{10}{*}{ rs2738780 } & Codominant & $\mathrm{C} / \mathrm{C}$ & $481(69.4 \%)$ & $410(74.4 \%)$ & 1 & 0.13 \\
\hline & & $\mathrm{T} / \mathrm{C}$ & $197(28.4 \%)$ & $133(24.1 \%)$ & $0.79(0.61-1.02)$ & \\
\hline & & $\mathrm{T} / \mathrm{T}$ & $15(2.2 \%)$ & $8(1.4 \%)$ & $0.63(0.26-1.49)$ & \\
\hline & Dominant & $\mathrm{C} / \mathrm{C}$ & $481(69.4 \%)$ & $410(74.4 \%)$ & 1 & 0.051 \\
\hline & & $\mathrm{T} / \mathrm{C}-\mathrm{T} / \mathrm{T}$ & $212(30.6 \%)$ & $141(25.6 \%)$ & $0.78(0.61-1.00)$ & \\
\hline & Recessive & $\mathrm{C} / \mathrm{C}-\mathrm{T} / \mathrm{C}$ & $678(97.8 \%)$ & $543(98.5 \%)$ & 1 & 0.35 \\
\hline & & $\mathrm{T} / \mathrm{T}$ & $15(2.2 \%)$ & $8(1.4 \%)$ & $0.67(0.28-1.58)$ & \\
\hline & Overdominant & $\mathrm{C} / \mathrm{C}-\mathrm{T} / \mathrm{T}$ & $496(71.6 \%)$ & $418(75.9 \%)$ & 1 & 0.088 \\
\hline & & $\mathrm{T} / \mathrm{C}$ & $197(28.4 \%)$ & $133(24.1 \%)$ & $0.80(0.62-1.03)$ & \\
\hline & Log-additive & --- & --- & --- & $0.79(0.63-0.99)$ & $0.044^{*}$ \\
\hline \multirow{10}{*}{ rs6062299 } & Codominant & $\mathrm{G} / \mathrm{G}$ & $534(77.2 \%)$ & $422(76.2 \%)$ & 1 & 0.018 \\
\hline & & $\mathrm{G} / \mathrm{C}$ & $155(22.4 \%)$ & $120(21.7 \%)$ & $0.98(0.75-1.28)$ & \\
\hline & & $\mathrm{C} / \mathrm{C}$ & $3(0.4 \%)$ & $12(2.2 \%)$ & $5.06(1.42-18.04)$ & \\
\hline & Dominant & $\mathrm{G} / \mathrm{G}$ & $534(77.2 \%)$ & $422(76.2 \%)$ & 1 & 0.68 \\
\hline & & $\mathrm{G} / \mathrm{C}-\mathrm{C} / \mathrm{C}$ & $158(22.8 \%)$ & $132(23.8 \%)$ & $1.06(0.81-1.38)$ & \\
\hline & Recessive & G/G-G/C & $689(99.6 \%)$ & $542(97.8 \%)$ & 1 & $0.005 *$ \\
\hline & & $\mathrm{C} / \mathrm{C}$ & $3(0.4 \%)$ & $12(2.2 \%)$ & $5.08(1.43-18.10)$ & \\
\hline & Overdominant & $\mathrm{G} / \mathrm{G}-\mathrm{C} / \mathrm{C}$ & $537(77.6 \%)$ & $434(78.3 \%)$ & 1 & 0.75 \\
\hline & & $\mathrm{G} / \mathrm{C}$ & $155(22.4 \%)$ & $120(21.7 \%)$ & $0.96(0.73-1.25)$ & \\
\hline & Log-additive & -- & --- & --- & $1.14(0.89-1.45)$ & 0.3 \\
\hline \multirow{10}{*}{ rs3787098 } & Codominant & $\mathrm{G} / \mathrm{G}$ & $551(79.4 \%)$ & $435(78.5 \%)$ & 1 & 0.017 \\
\hline & & $\mathrm{G} / \mathrm{A}$ & $140(20.2 \%)$ & $107(19.3 \%)$ & $0.97(0.73-1.28)$ & \\
\hline & & $\mathrm{A} / \mathrm{A}$ & $3(0.4 \%)$ & $12(2.2 \%)$ & $5.07(1.42-18.06)$ & \\
\hline & Dominant & $\mathrm{G} / \mathrm{G}$ & $551(79.4 \%)$ & $435(78.5 \%)$ & 1 & 0.71 \\
\hline & & $\mathrm{G} / \mathrm{A}-\mathrm{A} / \mathrm{A}$ & $143(20.6 \%)$ & $119(21.5 \%)$ & $1.05(0.80-1.39)$ & \\
\hline & Recessive & G/G-G/A & $691(99.6 \%)$ & $542(97.8 \%)$ & 1 & $0.004 *$ \\
\hline & & $\mathrm{A} / \mathrm{A}$ & $3(0.4 \%)$ & $12(2.2 \%)$ & $5.10(1.43-18.15)$ & \\
\hline & Overdominant & $\mathrm{G} / \mathrm{G}-\mathrm{A} / \mathrm{A}$ & $554(79.8 \%)$ & $447(80.7 \%)$ & 1 & 0.7 \\
\hline & & $\mathrm{G} / \mathrm{A}$ & $140(20.2 \%)$ & $107(19.3 \%)$ & $0.95(0.72-1.25)$ & \\
\hline & Log-additive & --- & --- & --- & $1.14(0.89-1.47)$ & 0.3 \\
\hline
\end{tabular}

OR, odd ratio; CI, confidence interval AIC, Akaike's information criterion; BIC, Bayesian information criterion ; * $p \leq 0.05$ indicates statistical significance. 
Table 4: RTEL1 haplotypes and their association with LC risk.

\begin{tabular}{|c|c|c|c|}
\hline Haplotype & Freq & OR $(95 \%$ CI $)$ & $p$-value \\
\hline $\mathrm{CCC}$ & 0.7255 & 1 & --- \\
\hline CTC & 0.1501 & $0.80(0.63-1.00)$ & $0.05^{*}$ \\
\hline TCT & 0.1224 & $1.00(0.78-1.26)$ & 0.97 \\
\hline rare & 0.002 & $1.78(0.13-23.93)$ & 0.66 \\
\hline
\end{tabular}

Global haplotype association $p$-value: 0.23

$\mathrm{CI}$, confidence interval; OR, odd ratio

${ }^{*} p \leq 0.05$ indicates statistical significance.

Some limitations in our case-control study were notable. First, the sample size was relatively small. Second, correlations between genetic polymorphisms and clinicopathologic types (squamous cell carcinoma, adenocarcinoma and other histological LC types) were not considered. These limitations will be addressed in future studies.

In conclusion, our study provides new evidence of the relationship between RTEL1 and LC, and specific RTEL1 SNPs may increase or decrease LC risk in the Chinese Han population.

\section{MATERIALS AND METHODS}

\section{Study population and procedures}

Research subjects included 554 lung cancer patients and 696 cancer-free controls. Patients were recruited from January 2011 to February 2015 at the Affiliated Hospital of the Xizang Minzu University in China. Lung cancer patients had no history of other malignancy or prior chemotherapy or radiotherapy. Controls had no acute or chronic pathology. Their cancer-free state was confirmed by testing carcinoembryonic antigen and $\alpha$-fetoprotein plasma levels. The study protocol was approved by the Institutional Research Ethic Committee of the Affiliated Hospital of the Xizang Minzu University in China, Xizang Minzu University and written consent was obtained from all subjects. Two ml of whole blood was collected from each patient in K2 EDTA tubes and stored at $-20^{\circ} \mathrm{C}$ for further study.

\section{SNP selection and genotyping}

Based on SNPs with minor allele frequencies (MAF) greater than 0.05 identified in a prior $\mathrm{LC}$ association analysis of a CHB (Han Chinese in Beijing, China) population, we chose seven RTEL1 SNPs for further genotyping. We used the genomic DNA purification kit (GoldMag Co. Ltd., Xi'an, China) to extract DNA from peripheral blood samples. DNA sample concentrations and purities were assessed by absorbance at $260 \mathrm{~nm}$ with a NanoDrop 2000 (Thermo Scientific, Waltham, MA). Contamination by proteins was assessed by measuring absorbance at $280 \mathrm{~nm}$ and calculating 260/280 ratios. MassARRAY Assay Design
3.0 Software (Sequenom, San Diego, CA, USA) was used to design the PCR assay and PLEX single-base extension primers for the Multiplexed SNP MassEXTEND assay [28]. Sequenom Typer 4.0 software (Sequenom) was used for data management and analyses [29].

\section{Statistical analysis}

The statistical analysis was performed using SPSS 17.0 software (SPSS, Inc.). Hardy-Weinberg equilibrium (HWE) was tested separately for RTEL1 genotypes in the case and control subjects. Odds ratios (OR) and 95\% confidence intervals (CI) were used to evaluate relative risk. All $p$ values were two-tailed and $p<0.05$ was considered statistically significant.

\section{CONFLICTS OF INTEREST}

The authors declare no conflicts of interest.

\section{GRANT SUPPORT}

This work is supported by the Project of Health Science and research project of Shaanxi Province in 2014 (2014D47), the National Natural Science Foundation of China (No.81302029), the Natural Science Foundation of Shaanxi Province of China (No.2014JQ4149), Fundamental Research Funds for the Central Universities in Xi'an Jiaotong University (No.xjj2015086) and the China Postdoctoral Science Foundation (No.2015M570841).

\section{REFERENCES}

1. Collins LG, Haines C, Perkel R, Enck RE. Lung cancer: diagnosis and management. Am Fam Physician. 2007; 75:56-63.

2. Chen W, Zheng R, Zhang S, Zhao P, Zeng H, Zou X, He J. Annual report on status of cancer in China, 2010. Chinese $J$ Cancer Res. 2014; 26:48.

3. Bach PB, Cramer LD, Warren JL, Begg CB. Racial differences in the treatment of early-stage lung cancer. New Engl J Med. 1999; 341:1198-1205. 
4. Radziszewska A, Karczmarek-Borowska B, GrądalskaLampart M, Filip A. [Epidemiology, prevention and risk morbidity factors for lung cancer]. Polski merkuriusz lekarski: organ Polskiego Towarzystwa Lekarskiego. 2015; 38:113-118.

5. Heighway J, Thatcher N, Cerny T, Hasleton PS. Genetic predisposition to human lung cancer. British journal of cancer. 1986; 53:453.

6. Laitinen VH, Rantapero T, Fischer D, Vuorinen EM, Tammela TL, Wahlfors T, Schleutker J. Fine - mapping the $2 q 37$ and 17q11.2 - q22 loci for novel genes and sequence variants associated with a genetic predisposition to prostate cancer. Int J Cancer. 2015; 136:2316-2327.

7. Chen Y, McGee J, Chen X, Doman TN, Gong X, Zhang Y, Hamm N, Ma X, Higgs RE, Bhagwat SV. Identification of druggable cancer driver genes amplified across TCGA datasets. PloS one. 2014; 9:e98293.

8. Ballew BJ, Joseph V, De S, Sarek G, Vannier J-B, Stracker T, Schrader KA, Small TN, O'Reilly R, Manschreck C. A recessive founder mutation in regulator of telomere elongation helicase 1, RTEL1, underlies severe immunodeficiency and features of Hoyeraal Hreidarsson syndrome. PLoS Genet. 2013; 9:e1003695.

9. Ballew BJ, Yeager M, Jacobs K, Giri N, Boland J, Burdett L, Alter BP, Savage SA. Germline mutations of regulator of telomere elongation helicase 1, RTEL1, in dyskeratosis congenita. Hum Genet. 2013; 132:473-480.

10. Jin $\mathrm{G}, \mathrm{Xu} \mathrm{L}$, Shu Y, Tian T, Liang J, Xu Y, Wang F, Chen J, Dai J, Hu Z. Common genetic variants on 5 p15. 33 contribute to risk of lung adenocarcinoma in a Chinese population. Carcinogenesis. 2009; 30:987-990.

11. Landi MT, Chatterjee N, Yu K, Goldin LR, Goldstein AM, Rotunno M, Mirabello L, Jacobs K, Wheeler W, Yeager M. A genome-wide association study of lung cancer identifies a region of chromosome $5 \mathrm{p} 15$ associated with risk for adenocarcinoma. Am J Hum Genet. 2009; 85:679-691.

12. McKay JD, Hung RJ, Gaborieau V, Boffetta P, Chabrier A, Byrnes G, Zaridze D, Mukeria A, Szeszenia-Dabrowska N, Lissowska J. Lung cancer susceptibility locus at 5p15. 33. Nat Genet. 2008; 40:1404-1406.

13. Pierik M, Joossens S, Van Steen K, Van Schuerbeek N, Vlietinck R, Rutgeerts P, Vermeire S. Toll- like receptor - $1,-2$, and - 6 polymorphisms influence disease extension in inflammatory bowel diseases. Inflamm Bowel Dis. 2006; 12:1-8.

14. Ding H, Schertzer M, Wu X, Gertsenstein M, Selig S, Kammori M, Pourvali R, Poon S, Vulto I, Chavez E. Regulation of murine telomere length by Rtel: an essential gene encoding a helicase-like protein. Cell. 2004; 117:873-886.

15. de Lange T. How telomeres solve the end-protection problem. Science (New York, NY). 2009; 326:948.

16. Harley CB. Human ageing and telomeres. Ciba Found Symp. 1997; 129-139.

17. Günes C, Rudolph KL. The role of telomeres in stem cells and cancer. Cell. 2013; 152:390-393.
18. Barber LJ, Youds JL, Ward JD, McIlwraith MJ, O’Neil NJ, Petalcorin MI, Martin JS, Collis SJ, Cantor SB, Auclair M. RTEL1 maintains genomic stability by suppressing homologous recombination. Cell. 2008; 135:261-271.

19. Youds JL, Mets DG, McIlwraith MJ, Martin JS, Ward JD, ONeil NJ, Rose AM, West SC, Meyer BJ, Boulton SJ. RTEL-1 enforces meiotic crossover interference and homeostasis. Science. 2010; 327:1254-1258.

20. Liu Y, Shete S, Etzel CJ, Scheurer M, Alexiou G, Armstrong G, Tsavachidis S, Liang F-W, Gilbert M, Aldape K. Polymorphisms of LIG4, BTBD2, HMGA2, and RTEL1 genes involved in the double-strand break repair pathway predict glioblastoma survival. Journal of Clinical Oncology. 2010; 28:2467-2474.

21. Vilenchik MM, Knudson AG. Endogenous DNA doublestrand breaks: production, fidelity of repair, and induction of cancer. Proceedings of the National Academy of Sciences. 2003; 100:12871-12876.

22. Pierce AJ, Stark JM, Araujo FD, Moynahan ME, Berwick M, Jasin M. Double-strand breaks and tumorigenesis. Trends Cell Biol. 2001; 11:S52-S59.

23. Bai C, Connolly B, Metzker ML, Hilliard CA, Liu X, Sandig V, Soderman A, Galloway SM, Liu Q, Austin CP. Overexpression of M68/DcR3 in human gastrointestinal tract tumors independent of gene amplification and its location in a four-gene cluster. Proceedings of the National Academy of Sciences. 2000; 97:1230-1235.

24. Pitti RM, Marsters SA, Lawrence DA, Roy M, Kischkel FC, Dowd P, Huang A, Donahue CJ, Sherwood SW, Baldwin DT. Genomic amplification of a decoy receptor for Fas ligand in lung and colon cancer. Nature. 1998; 396:699-703.

25. Wong N, Lai P, Lee S-W, Fan S, Pang E, Liew C-T, Sheng Z, Lau JW-Y, Johnson PJ. Assessment of genetic changes in hepatocellular carcinoma by comparative genomic hybridization analysis: relationship to disease stage, tumor size, and cirrhosis. Am J pathol. 1999; 154:37-43.

26. Song X, Zhou K, Zhao Y, Huai C, Zhao Y, Yu H, Chen Y, Chen G, Chen H, Fan W. Fine mapping analysis of a region of 20q13. 33 identified five independent susceptibility loci for glioma in a Chinese Han population. Carcinogenesis. 2012:bgs117.

27. Zhang C, Lu Y, Zhang X, Yang D, Shang S, Liu D, Jiang K, Huang W. The role of the RTEL1 rs2297440 polymorphism in the risk of glioma development: a meta-analysis. Neurol Sci. 2016; 37:1023-1031.

28. Gabriel S, Ziaugra L, Tabbaa D. SNP genotyping using the Sequenom MassARRAY iPLEX platform. Current protocols in human genetics / editorial board, Jonathan L Haines [et al]. 2009; Chapter 2:Unit 212.

29. Thomas RK, Baker AC, Debiasi RM, Winckler W, Laframboise T, Lin WM, Wang M, Feng W, Zander T, MacConaill L, Lee JC, Nicoletti R, Hatton C, et al. Highthroughput oncogene mutation profiling in human cancer. Nat Genet. 2007; 39:347-351. 